\title{
10 The predicaments of European disabled people
}

\author{
Vasco Reis and André Freitas
}

\begin{abstract}
In 2012, around 59 million Europeans (aged 15 and over) reported a disability with regards to mobility or transport. Disabled people have specific mobility problems depending on the cause of their impairment (e.g. reduced vision, hearing or movement, environmentally or psychologically challenged).

There is now wide recognition of the importance of issues such as access to transport and the impact that it can have on the quality of life and independence of disabled people. Yet, there is no general agreement nor clear understanding about most disabled population mobility habits. People with a disability are a very heterogeneous group with several different types of impairment, which inhibit their travel options in different ways and consequently their personal quality of life and independence.
\end{abstract}

\section{Conceptual discussion}

On 13 December 2006, the Convention on the Rights of Persons with Disabilities and its Optional Protocol was adopted. The negotiation took place between 2002 and 2006, making it the fastest negotiated human rights treaty. ${ }^{1}$ At the time, a central aspect of the Convention was to raise the cultural and social position of disabled people from objects or recipients of charity, social protection or medical treatment to (human) subjects with rights. As pointed out by Cuthbertson (2015), the prevalent symbol of human power and privilege is of a walking unaided person. Other forms of locomotion (e.g. a wheelchair) carry strong negative cultural meanings.

The negative connotation of disability is grounded in deep-rooted stereotypes, myths and ideologies, nurtured over time. Oliver (1990) argued that disabled people are regarded as problems since they deviate from the dominant culture's view of what is expected, normal or socially accepted. Literature clearly indicates that disabled people face social and spatial exclusion. Disabled people have a higher probability of living in poor neighbourhoods, 
with inadequate access to transport, equipment, services or employment (Gleeson 2006). By way of example, even nowadays, many underground stations are inaccessible to wheelchairs. Disabled people are often trapped in a self-reinforcing vicious circle of poverty and isolation.

Yet, disability is not limited to locomotion. Urry (2007) identified five forms of interdependent mobility and, hence, of disability: corporeal, imaginative, virtual, communicative and mobility of objects (circulatory and logistical). Communication is of particular relevance. The recent technological developments, notably regarding Information and Communication Technologies, brought an array of new technology-driven mobility services such as ride hailing (e.g. UBER), micro-mobility services and paperless ticketing systems. These new services have been designed for non-disabled people. Disabled people may find themselves even more excluded from the mobility system. Such a situation is, in itself, paradoxical. Newer regimes and ideologies, such as neoliberalism, should have brought unprecedented freedom, freeing disabled people from the various forms of immobilities. Instead, they are creating new forms of exclusion and injustice, further aggravating their already inferior position. The day-to-day reality of disabled people is of restricted mobility, immobility or a continuum of situations that serve to highlight their impairment and inferiority (Imrie 2000).

Urbanisation seems to play a relevant role in the level of exclusion. Peri-urban and rural areas exhibit distinctive organisation, dynamics and features of mobilities. Services tend to be located further away and mobility services are less abundant and accessibility is also inferior. Specialised services for disabled people are scarce or, when available, must be requested in advance.

\section{Quantitative assessment and characteristics}

A disabled person or a person with reduced mobility is usually considered to be any given person whose mobility while using a mode of transport is reduced because of physical disabilities (sensory or affecting mobility, being permanent or temporary), intellectual impairment or any other cause of disability, or age, which requires appropriate and specific attention as well as an adaptation of the transport service made available to all passengers and all their particular needs.

Long-term physical, mental, intellectual or sensory impairment in its interaction with different types of transport-related barriers may affect their full and effective participation in society on an equal basis with others (United Nations 2008). Nonetheless, there are multiple dimensions that can prevent people from performing one or several basic activities.

The definitions that tend to be applied for statistical purposes depend mostly on the number of questions that can be asked about issues such as impairments, limitations or barriers to participation. Table 10.1 details the differences in data sources for EU statistics when addressing the topic of disability. 
Table 10.1 Overview of data sources for EU statistics on disability

\begin{tabular}{|c|c|c|c|c|}
\hline & $\begin{array}{l}\text { European } \\
\text { health } \\
\text { and social } \\
\text { integration } \\
\text { survey } \\
\text { (EHSIS) }\end{array}$ & $\begin{array}{l}\text { European health } \\
\text { interview survey } \\
\text { (EHIS) }\end{array}$ & $\begin{array}{l}\text { Statistics } \\
\text { on income } \\
\text { and living } \\
\text { conditions } \\
(\text { SILC) }\end{array}$ & $\begin{array}{l}\text { Ad hoc module } \\
\text { on employment of } \\
\text { disabled people in } \\
\text { the labour force } \\
\text { survey (LFS) }\end{array}$ \\
\hline Main topics covered & $\begin{array}{l}\text { Disability } \\
\text { as defined } \\
\text { by the UN } \\
\text { Convention }\end{array}$ & $\begin{array}{l}\text { Health status, } \\
\text { health } \\
\text { determinants } \\
\text { and health } \\
\text { care use }\end{array}$ & $\begin{array}{l}\text { Income, } \\
\text { social } \\
\text { inclusion } \\
\text { and living } \\
\text { conditions }\end{array}$ & $\begin{array}{l}\text { Employment of } \\
\text { disabled people }\end{array}$ \\
\hline Legal basis & No & Yes & Yes & Yes \\
\hline Periodicity & Once (2012) & 5-yearly & Annual & $\begin{array}{l}\text { Irregular } \\
\quad(2002 \text { and 2011) }\end{array}$ \\
\hline $\begin{array}{l}\text { Limitations in usual } \\
\text { activities caused by a } \\
\text { health problem }\end{array}$ & Yes & Yes & Yes & \\
\hline $\begin{array}{l}\text { Difficulties in carrying } \\
\text { out basic activities }\end{array}$ & Yes & Yes & & Yes \\
\hline $\begin{array}{l}\text { Difficulties in performing } \\
\text { personal care activities }\end{array}$ & Yes & $\begin{array}{c}\text { Yes (persons } \\
\text { aged } 65+\text { ) }\end{array}$ & & \\
\hline $\begin{array}{l}\text { Difficulties in performing } \\
\text { household care } \\
\text { activities }\end{array}$ & Yes & $\begin{array}{l}\text { Yes (persons } \\
\text { aged } 65+)\end{array}$ & & \\
\hline $\begin{array}{l}\text { Participation restriction } \\
\text { linked to a health } \\
\text { condition and/ or a } \\
\text { basic activity difficulty }\end{array}$ & Yes & & & \\
\hline $\begin{array}{l}\text { Limitation in work caused } \\
\text { by health problems } \\
\text { and/ or difficulties in } \\
\text { basic activities }\end{array}$ & Yes & & & Yes \\
\hline
\end{tabular}

Source: Eurostat (2018).

Despite the existence of a significant number of questions related to impairments, limitations and barriers to participation ${ }^{2}$, we can see in Table 10.2 the distribution of all EU citizens (aged 15 and over) who report a disability by categories of life areas in which this disability is a source of constraint and by European country.

In 2012, 70 million people reported disabilities (aged 15 and over) in the EU-27. This number does not mean that all these persons have mobility problems. Also, in 2012, around 44.5 million people reported some sort of difficulty in conducting basic activities (including mobility) in the EU. In the same year, $52.9 \%$ (37.03 million) and 31.7\% (22.19 million) of the total EU population (aged 15 and over) reported a disability in mobility and transport life areas, respectively (Eurostat 2018). 


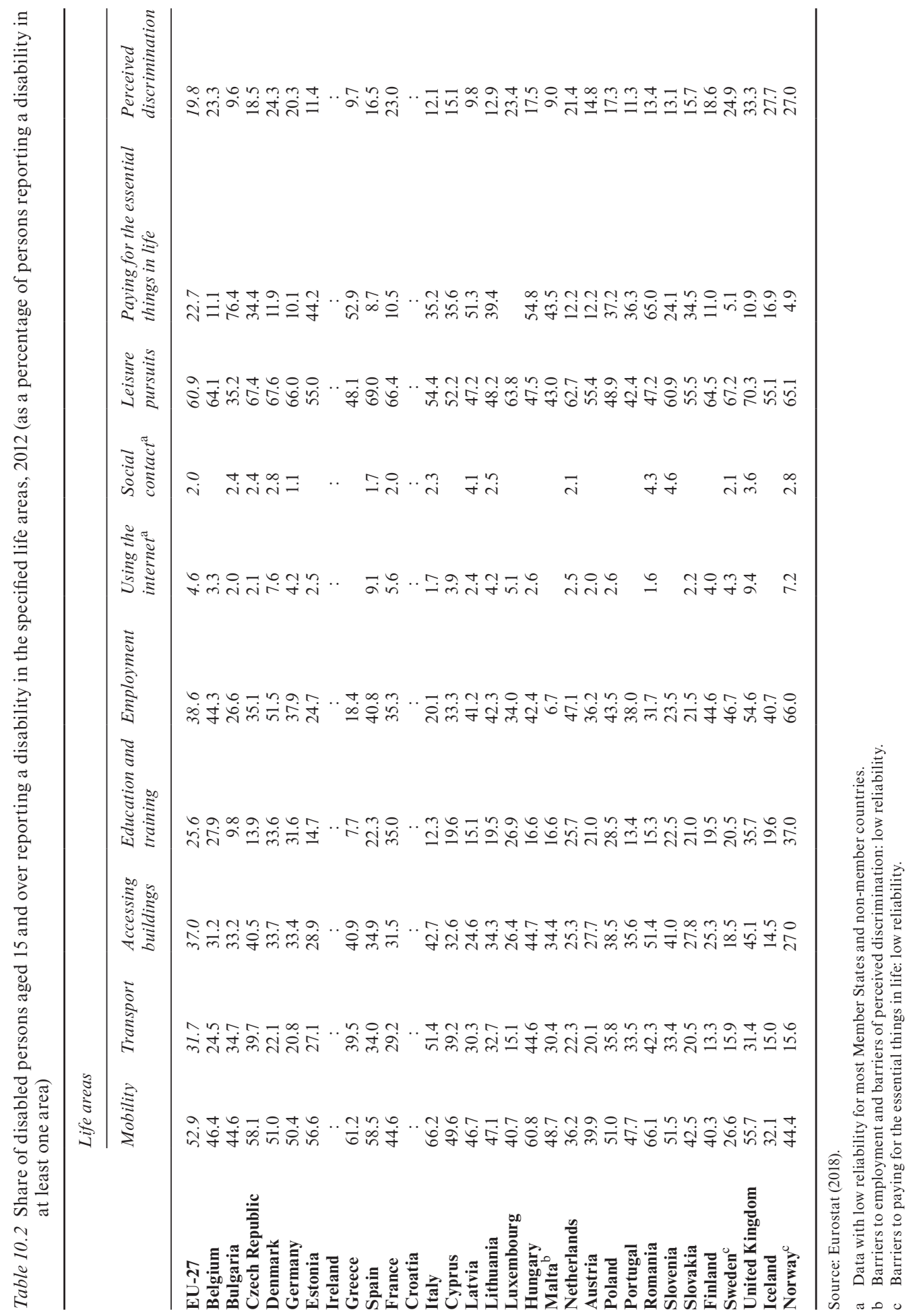


It was in two life areas where more than half of all people with disabilities (in the EU-27) reported that their disability was the cause of their restriction on participation in 2012: leisure pursuits (in other words, hobbies or interests that involve spending time with other people) and mobility (defined here as the ability to leave one's own home).

Table 10.2 confirms these arguments in all the EU member states and also covers other aspects like persons reporting a disability in education and training or in social contacts, for example. It is worth mentioning that, in that same year, women reported higher levels of disability regarding mobility ( $54 \%$ in women vs. $48 \%$ in men) and regarding transport (33\% in women vs. $28 \%$ in men) alike.

Analysing all the barriers to participation that people with disabilities face recalls some of the demographic categories in that we can find higher or lower prevalence of disability. So, this prevalence of disability was higher for women (19.9\%) than for men (15.1\%) as evident in Figure 10.1 shown below (Eurostat 2018). Disabled women seemed more likely to report barriers to mobility, transport and to the accessibility of buildings than disabled men. The prevalence of disability was also much higher for people aged 65 and over $(35.6 \%)$ than for those aged $45-54(18.8 \%)$ or aged $15-44(8.5 \%)$, as confirmed in Figure 10.1.

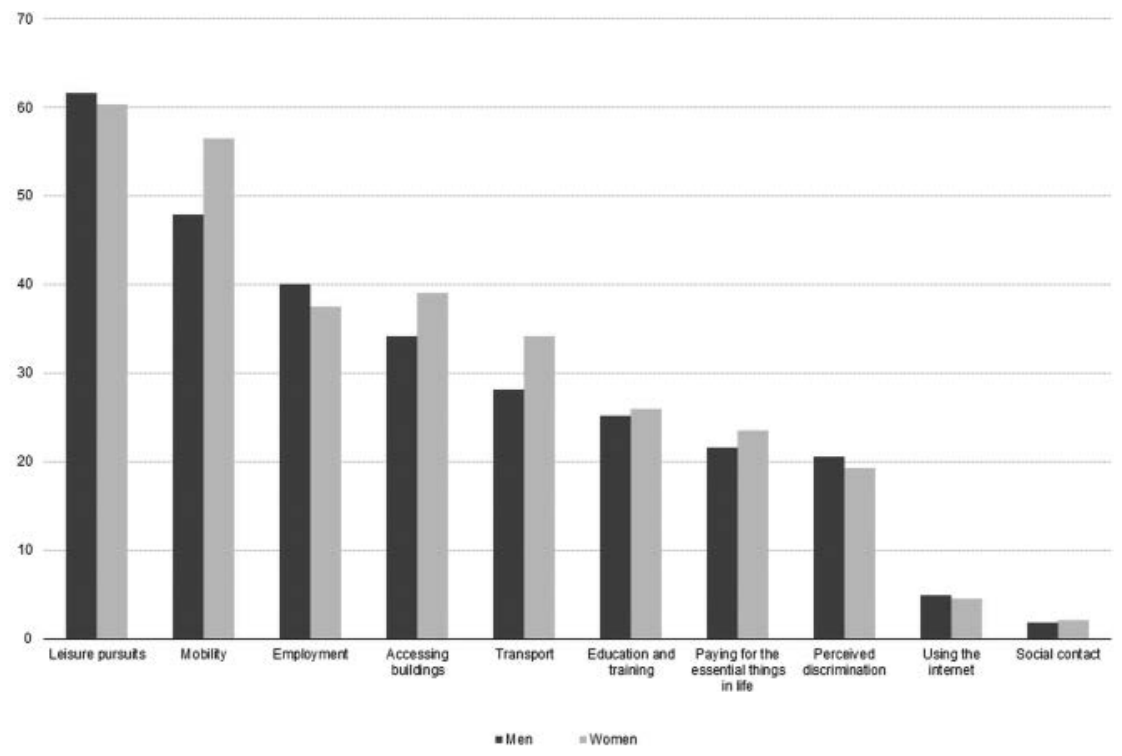

(") Estimates.

Source: Eurostat (online data code: hith_dsiogo)

Figure 10.1 Share of disabled persons aged 15 and over reporting a disability in the specified life areas, by gender, EU-27, 2012 (estimates) (as a percentage of persons reporting a disability in at least one area).

Source: Eurostat 2018. 


\section{Mobility-related characteristics}

For the Europe 2020 strategy to be successful, the full economic and social participation of people with disabilities is essential.

Research has shown that disabled people travel less than non-disabled people. In a highly dense and urbanised context, for example, the public authority Transport for London (Transport for London 2014) has realised that whilst disabled people fundamentally have a similar modal share as non-disabled Londoners, the frequency of using transport is much lower among disabled persons: 1.97 journeys per weekday among disabled Londoners vs. 2.77 for non-disabled Londoners. "Public transport types are also less commonly used by disabled Londoners than non-disabled Londoners, 60 per cent of disabled Londoners have used any public transport (excluding walking) in the last year compared with 73 per cent of nondisabled" (Transport for London 2014, 196). Accessibility-related barriers top-rank the main obstacles that Londoner disabled persons encounter whilst using public transport. Such transportation obstacles allow disabled people even fewer opportunities to interact with their communities, thus enhancing social exclusion in what can be regarded as a vicious circle which is intensified in the presence of combined social layer groups (e.g. elderly people with a disability).

A study in England and Wales aimed to identify the attitudes of disabled people to public transport in the respective regions (DPTAC 2002, 14), making an effort to represent more effectively the broad range of disabled people when preparing advice to government. This study mentions that, when asked unprompted about their local concerns, transport issues are top of disabled people's list $(48 \%)$, followed by crime $(22 \%)$, environment $(16 \%)$ and social services/facilities/community $(16 \%)$. Transport issues for disabled people can be understood as: (i) the inaccessibility of public transport, where provision often fails to meet the diverse needs of young wheelchair users (transport disability); (ii) the importance of emotion in experiences of transport and the anxieties produced by inaccessible transport; and (iii) the centrality of private forms of transport in accessing leisure (mobility dependency) (Pyer and Tucker 2014, 38).

Specific transport concerns include (DPTAC 2002):

- Difficulty in using public transport (16\%);

- Frequency of public transport (16\%);

- Unreliable buses/trains (10\%);

- Traffic congestion (8\%);

- The speed of motorists (8\%);

- $\quad$ Shortage of car parking $(7 \%)$;

- Traffic noise (3\%); and

- The level of road accidents $(2 \%)$. 
With the exception of the difficulty felt while using transport, these issues are similar to the general public. Hence, it is possible to assume that people with reduced mobility have special needs because of their physical or psychological limitations, but they have similar needs as non-disabled persons as well. Comparable results were found in more recent research projects such as the one carried out in 2014 by Birgitta Thorslund about the mobility behaviour among people with one of the most frequent sensory deficits in humans, hearing loss. These results show that "a higher degree of hearing loss was associated with less likelihood of having a driver's license. However, individuals with hearing loss who had a driver's license, drove as much as normal hearing drivers" (Thorslund 2014, 28). From this study, it was concluded that hearing loss is associated with higher use of private transport, the car being perceived as a "compensational tool for functional limitations" (Thorslund 2014, 55). However, it has no effect on the distribution of how much each type of transportation was used.

In contrast, Canadian-based data show a dissimilar trend. In this respect, a study shows that disabled Canadians travel considerably less and over shorter distances and have less access to key services than the average Canadian population (Paez et al. 2009). Karen Lucas, referring to the Canadian study, therefore argues that disability impacts very negatively on the well-being of disabled persons, reflected in the fact that they perform fewer trips than the non-disabled population. Their social lives are therefore hindered by limited access to transportation (Lucas 2012).

American researcher Bascom (Bascom 2017) examined how individuals with disabilities are meeting their transportation needs. He hypothesised (and effectively concluded) that individuals with disabilities who have stronger and wider social networks are more likely to ride-share and have access to other forms of transportation assistance than those who have weaker social networks, who will be much more likely to rely on public transportation. This is a concrete reflection of the widely popular sociological network theory of interpersonal ties, developed mostly by American sociologists in the 1970s.

\section{Mobility-related disadvantages}

Several scholars have related spatial and social inequalities in access to transport for particular social groups (Kenyon et al. 2002, Preston and Rajé 2007). There is now wide recognition of the importance of issues such as access to transport and the impact that it can have on the quality of life and independence of people with disabilities, as they have specific mobility problems. The characterisation of the mobility disadvantages in this segment is particularly difficult, due to the wide diversity of disabilities or impairments. As previously discussed, the European Parliament defined five types of disabilities (European Parliament and the Council of the European 
Union 2006). What follows is a brief identification of the key mobility disadvantages per type:

1 Reduced vision (vision impaired) - key challenges include: situational awareness, wayfinding in terminals, acquisition of tickets and understanding any visual-based information;

2 Reduced hearing (hard of hearing) - key challenges include: understanding any sound-based information, which is of particular relevance in emergency situations, or even detecting any risky situation.

3 Reduced movement (mobility impaired) - key challenges are linked with the need to overcome different heights (e.g. different levels of the terminal, entering or exiting vehicles) and to overcome gaps (e.g. between the terminal platform and vehicle).

4 Environmentally challenged (allergic) - key challenges are related to a higher-than-average concentration of pollutants in or around vehicles and terminals. Several vehicles are powered by internal combustion engines (e.g. buses, taxis, aircraft, ships). In addition, in/around terminals (e.g. airports, bus terminals), vehicles are frequently involved in manoeuvres or move at low speeds. These are two situations where internal combustion engines are the least efficient (producing the highest levels of emissions). Moreover, certain terminals and/or routes (e.g. metropolitan) are covered, which precludes efficient air circulation and favours the concentration and deposition of pollutants. People with health conditions may be particularly affected in these areas.

5 Psychologically/mentally cognitively challenged - a key challenge is related to the ability of the person to understand how to use the transport system, including knowing what ticket to buy, wayfinding in the terminal and situation awareness.

People with reduced mobility are less likely to benefit from access to standard means of transport if the initial design does not take their needs into account. Hence, persons with a disability tend to rely on private transport to access services and for day-to-day activities such as shopping and participating in social activities. In fact, the single most frequently used mode of transport by people with reduced mobility is the car as passenger (DPTAC 2002).

Arguably, in order to realise many opportunities for disabled people to participate fully in society, it is common for them to depend on the support of relatives who chauffeur them by private transport or accompany them on public transport.

Pyer and Tucker (2014) conducted an ethnographic investigation focused on teenagers in wheelchairs. They concluded that the main symptom of mobility poverty that affects this group results from inaccessibility to public transport vehicles, which seems to be an additional reason for applying the concept of "forced car ownership". This trend is consistent with data from 
the UK Department for Transport, mentioned by these authors, which point out that car ownership among a household of disabled people is well above the national average for families with dependent children. Even though not representative of each single type of impairment, the main conclusion that arises from this investigation is therefore that "the availability of private cars enabled access to a range of leisure spaces which would otherwise have been closed-down to many if they had been solely reliant on public transport" (Pyer and Tucker 2014, 48). The findings of Pyer and Tucker (2014) about the main source of exclusion are perfectly aligned with the ones from the Directorate-General for Internal Policies (Samek Lodovici and Torchio 2015), which highlight physical barriers and most notably public transport vehicle design as the main issue for the exclusion of people with reduced mobility.

To counteract these numbers and increase the number of people using public transport, national governments are introducing several new policy frameworks that intend, on the one hand, to contribute to the deployment of large infrastructure enhancements, conveying inclusive layouts for example and, on the other hand, to offer concessionary bus travel. In general, the take-up of concessionary passes is high, as demonstrated in this UK example: "older and disabled concessionary pass holders collectively make around 1.2 billion bus journeys, accounting for almost one in four of all journeys on local bus services" (Greener Journeys 2014, 4) . $^{3}$

It is simultaneously important to keep in mind that enhancements required for the benefit of disabled persons also favour those who do not suffer from any transport impairment. Buses featuring a low floor or low entry were meant to provide easy access for wheelchairs but have a positive indirect effect on the boarding and alighting time of all public transport users. The gist of accessible environments is creatively captured by the following image (Figure 10.2).

To combine transport infrastructures with social inclusion layouts and policies is even more important if one assumes that the number of citizens with disabilities and/or functional limitations is likely to increase significantly with the ageing of the European Union's population. It is equally important to keep pace with the tourism-induced indirect economic effects. In general, the accessible tourism industry, which statistics show is flourishing (Bowtell 2015), affects a wider scale of economy through the so-called "multiplicator effects" (Rebstock 2017).

\section{Multiple socio-economic disadvantages}

In the European statistics on income and living conditions (also known as EU-SILC ${ }^{4}$ ), disability is narrowed according to the concept of a global activity limitation, which it defines as a "limitation in activities people usually do because of health problems for at least the past six months" (Eurostat 2018). 


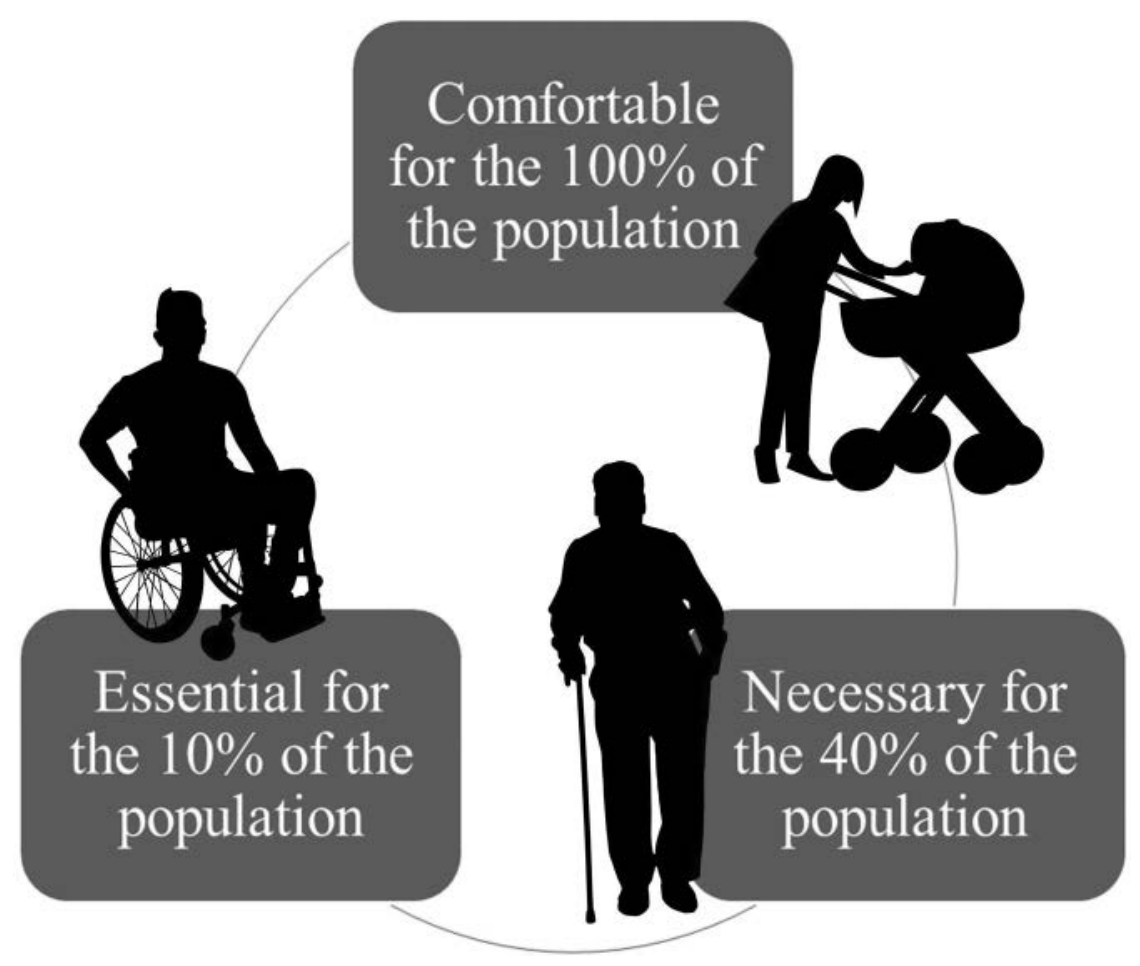

Figure 10.2 Accessibility for all.

Source: Authors, based on Rebstock 2017, 6.

In 2013, according to the indicator "at risk of poverty or social exclusion" (AROPE), about $30 \%$ of the population aged 16 or more in the EU-28 and having an activity limitation was at risk of poverty or social exclusion, compared with $22 \%$ of those with no limitation. Similar results were obtained for the at-risk-of-poverty rate (19\% vs. $15 \%)$, severe material deprivation rate $(13 \%$ vs. $8 \%)$ and the share of individuals aged less than 60 and living in households with very low work intensity ( $24 \%$ vs. $8 \%)$. It is important to note that significant differences across member states are visible, yet in all of them people without activity limitation are on average less exposed to the risk of poverty and social exclusion than those with some activity limitation (Eurostat 2015).

The prevalence of disability in the previous year (2012) was higher for people having completed at most lower secondary education (25.0\%) than for those having completed at most upper secondary or post-secondary, non-tertiary education $(15.4 \%)$ or tertiary education (11.0\%). Figure 10.3 may be a crucial support of such findings. It is also higher for retired persons 
$(34.3 \%)$ than for unemployed people $(20.5 \%)$, other economically inactive people $(20.2 \%)$ or employed persons $(8.0 \%)$.

People with activity limitation have to rely heavily on social transfers. At the EU-28 level, $68 \%$ of the population aged 16 and over with some sort of disability would have been at risk of poverty if social transfers (e.g. social benefits, allowances and pensions) had not taken place. On the other hand, $31 \%$ of the population with no activity limitation would have been at risk of poverty.

Another piece of relevant statistics is reported in Figure 10.3. People with disabilities having completed tertiary education were less likely to report a disability for mobility than other people with disabilities with lower levels of education. Less than 1 person out of 2 with basic activity difficulties was employed. The employment rate of people with basic activity difficulties in the EU-28 in 2011 was around $47.3 \%$.

One of the very few pieces of research about the relationship between disability and internet usage is noteworthy. This is a recent investigation

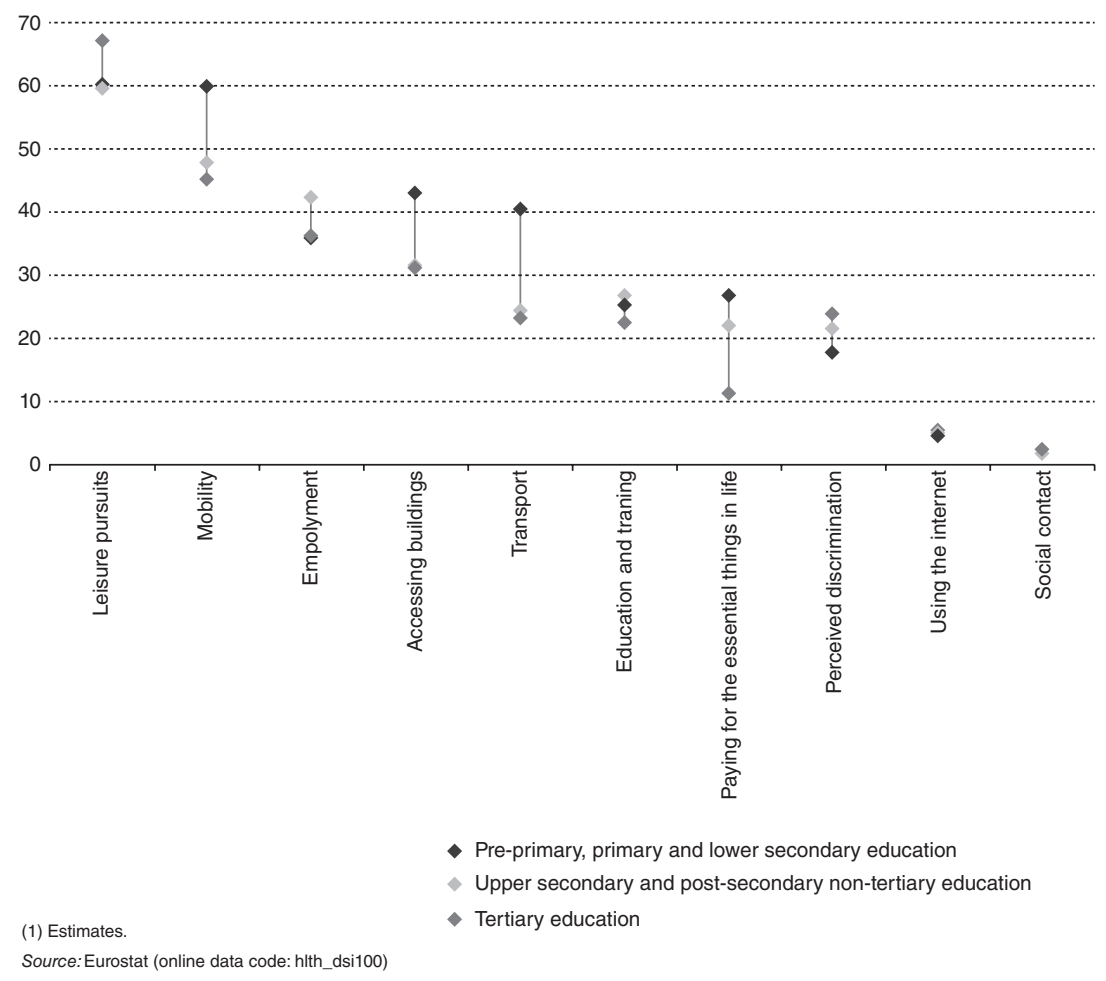

Figure 10.3 Share of disabled persons aged 15 and over with a disability in the specified life areas, by educational attainment, EU-27, 2012 (as a percentage of persons reporting a disability in at least one area).

Source: Eurostat 2018. 
conducted in Poland (Duplaga 2017) where the author found statistical evidence of the extent to which disabled people lag behind online activities.

Despite the factors determining the use of the Internet amongst disabled people being similar to those of the general population (e.g. place of residence, level of education, occupational status, net income), people with disabilities face a significant digital divide.

\section{Conclusions}

Mobility lies at the very heart of people's identities, opportunities and general life experiences. Yet, the research to understand the various perspectives of disability as a concept and social construct is only at the beginning (Goggin 2016). All in all, despite the conclusion that disabled people travel less than non-disabled even if they have similar needs (Bascom 2017, Transport for London 2014) and are granted incentives for using public transport (e.g. the UK Freedom Pass), it seems reasonable to assume by looking at previously mentioned dissimilar trends captured by several studies that there is no general agreement nor clear understanding about most disabled population mobility habits. People with a disability are a very heterogeneous group that may have several different types of impairment which inhibit their travel options differently and consequently their personal quality of life and independence. As such, this group is an indication of how contextual and relational mobility poverty actually is.

Proposing solutions to overcome mobility limitations faced by disabled people is far from trivial. Foremost, mobility is a multi-dimensional, multi-layered phenomenon. Secondly, there are many manifestations of disabilities, impacting a person's mobility capacity differently. Thirdly, the very notion of justice is deeply rooted in the norms and values of societies. Different justice theories lead to different policy measures, based on certain minimum thresholds that are valid for all or measures that enable specific vulnerable groups. This substantially leads to the question of whether accessibility or mobility of different groups is only absolutely, and also relationally, improved with respect to the highly mobiles or hypermobiles.

Other challenges loom ahead. General measures for different types of disability may be considered as a form of reducing the right to individualism or individual freedoms. Such freedoms lay at the core of liberalism and individualism, which are mainstream ideologies in most developed societies. On the other hand, tailored measures (i.e. affirmative actions) aimed at raising the mobility of the disabled are also potentially stigmatising. They will perpetuate and emphasise the inferior status of the disabled, due to the implementation of "special" measures. The creation of special mobility services like ADA paratransit in the US is precisely such an example one could argue because it has the aim of integrating/including disabled people into mainstream society, but, by confining their 
mobility to these special services, such people are actually prevented from socialising and participating in normal everyday life activities. U1timately, such good measures are worsening the gap between the disabled and non-disabled people. Moreover, such measures are, in practical terms, determining hierarchies of places where disabled people can and cannot participate. This is raising a new plethora of concerns linked with taking away a person's fundamental and universal right of mobility. Mobility measures concerning disabled people are commonly taken by transportation and planning experts who lack the required competences, authority or sensitivity.

There are no easy answers nor prescriptive measures to overcome the mobility impairment of disabled people. Moreover, as discussed earlier, disabled people often live in ghettoised regions with insufficient levels of participation and involvement in civil society (Imrie 2000). The development of new perspectives and political programmes are thus required to overcome the current injustice and raise the mobility of disabled people to satisfactory levels. Ultimately, disabled people will depend on specific factors such as the social, political and institutional structures of their local geographical contexts. After all, immobility rips a person from her/his fundamental human elements.

\section{Notes}

$1 \mathrm{https} / /$ www.un.org/development/desa/disabilities/convention-on-the-rights-ofpersons-with-disabilities.html

2 When the question relates to a person conducting basic activities, it can mean that we are referring to different types of barriers for any given person who reports a disability. It is possible that the same person may, ultimately, experience obstacles or barriers in several different types simultaneously.

3 It is interesting to cite here one of the most important results about the value for money delivered by the concessionary scheme in force in the UK, which altogether came across with a benefit cost ratio of 2.8 , which shows to what extent benefits outweigh costs.

4 EU-SILC consists of a multi-purpose instrument which has its focus mainly on income, with detailed data being collected on income components, mostly on personal income. This detailed data collection will also retrieve data information on social exclusion, housing conditions, labour, education and health information.

\section{References}

Bascom, Graydon. 2017. "Transportation related challenges for persons' with disabilities social participation.” Utah State University. https://digitalcommons.usu. edu/etd/5265. Accessed 9 July 2018.

Bowtell, James. 2015. "Assessing the value and market attractiveness of the accessible tourism industry in Europe. A focus on major travel and leisure companies." In Journal of Tourism Futures 1, no. 3: 203-222. https://doi.org/10.1108/ JTF-03-2015-0012. 
Cuthbertson, Anthony. 2015. Exoskeletons v wheelchairs: Disability advocates clash with futurists over|'offensivel' solution. In International Business Times. https:// www.ibtimes.co.uk/exoskeletons-vs-wheel-chairs-disability-advocates-clashfuturists-over-offensive-solution-1496178. Accessed 2 April 2020.

DPTAC. 2002. "Attitudes of disabled people to public transport research study conducted for disabled persons transport advisory committee." https://trimis. ec.europa.eu/sites/default/files/project/documents/20060811_110503_45123_ UG395_Final_Report.pdf. Accessed 2 April 2020.

Duplaga, Mariusz. 2017. "Digital divide among people with disabilities. Analysis of data from a nationwide study for determinants of Internet use and activities performed online." In PloS One 12, no. 6: e0179825-e0179825. https://doi.org/10.1371/ journal.pone.0179825.

European Parliament and the Council of the European Union. 2006. "Regulation (EC) No 1107/2006 concerning the rights of disabled persons and persons with reduced mobility when travelling by air." European Parliament; Council of the European Union. https://op.europa.eu/en/publication-detail/-/publication/88a98 652-688f-47ff-b79a-e55231b96a2a. Accessed 2 April 2020.

Eurostat. 2015. "Disability statistics - poverty and income inequalities." In Disability Statistics - Poverty and Income Inequalities. https:/ec.europa.eu/eurostat/ statistics-explained/index.php/Disability_statistics_-_poverty_and_income_in equalities. Accessed 2 April 2020.

Eurostat. 2018. "Disability statistics - barriers to social integration - statistics explained." https://ec.europa.eu/eurostat/statistics-explained/index.php?title=Archive: Disability_statistics_-_barriers_to_social_integration. Accessed 2 April 2020.

Gleeson, Brendan. 2006. "Changing practices, changing minds." In NDA 5th Annual Conference Civil, Cultural and Social Participation: Building and Inclusive Society, Dublin, Ireland. www.nda.ie. Accessed 2 April 2020.

Goggin, Gerard. 2016. "Disability and mobilities: Evening up social futures." In Mobilities 11, no. 4: 533-541. https://doi.org/10.1080/17450101.2016.1211821.

Greener Journeys. 2014. "The costs and benefits of concessionary bus travel for older and disabled people in Britain." https://greenerjourneys.com/wp-content/ uploads/2014/09/Concessionary-travel-costs-and-benefits-September-2014.pdf. Accessed on 9 July 2018.

Imrie, Rob. 2000. "Disability and discourses of mobility and movement." In Environment and Planning A 32, no. 9: 1641-1656. https://doi.org/10.1068/a331.

Kenyon, Susan, Glenn Lyons, and Jackie Rafferty. 2002. "Transport and social exclusion. Investigating the possibility of promoting inclusion through virtual mobility." In Journal of Transport Geography 10, no. 3: 207-219. https://doi.org/10. 1016/S0966-6923(02)00012-1.

Lucas, Karen. 2012. “Transport and social exclusion. Where are we now?" In Transport Policy 20: 105-113. https://doi.org/10.1016/j.tranpol.2012.01.013.

Oliver, Michael. 1990. The Politics of Disablement. London: Palgrave.

Paez, Antonio, Ruben G. Mercado, Steven Farber, Catherine Morency, and Matthew Roorda. 2009. Mobility and Social Exclusion in Canadian Communities. Toronto: Policy Research Directorate Strategic Policy and Research.

Preston, John, and Fiona Rajé. 2007. "Accessibility, mobility and transport-related social exclusion.” In Journal of Transport Geography 15, no. 3: 151-160. https://doi. org/10.1016/j.jtrangeo.2006.05.002. 
Pyer, Michelle, and Faith Tucker. 2014. "'With us, we, like, physically can't'. Transport, mobility and the leisure experiences of teenage wheelchair users." In Mobilities 12, no. 1: 36-52. https://doi.org/10.1080/17450101.2014.970390.

Rebstock, Markus, ed. 2017. "Economic benefits of improved accessibility to transport systems and the role of transport in fostering tourism for all." International Transport Forum Discussion Paper. https://www.itf-oecd.org/sites/default/files/ docs/improved-accessibility-fostering-tourism-for-all.pdf. Accessed 9 July 2018.

Samek Lodovici, Manuela, and Nicoletta Torchio. 2015. "Social inclusion in EU public transport." Policy Department B: Structural and Cohesion Policies European Parliament. Brussels. http://www.europarl.europa.eu/RegData/etudes/ STUD/2015/540351/IPOL_STU(2015)540351_EN.pdf. Accessed 13 June 2018.

Thorslund, Birgitta. 2014. Effects of Hearing Loss on Traffic Safety and Mobility. Linköping: Linköping University Electronic Press. http://liu.diva-portal.org/ smash/get/diva2:762084/FULLTEXT01.pdf. Accessed 2 April 2020.

Transport for London. 2014. "Understanding the travel needs of London's diverse communities. A summary of existing research." http://content.tfl.gov.uk/ understanding-the-travel-needs-of-london-diverse-communities.pdf. Accessed 13 June 2018.

United Nations, Department of Economic and Social Affairs. 2008. "Convention on the rights of persons with disabilities. United Nations." https://www. un.org/development/desa/disabilities/convention-on-the-rights-of-persons-withdisabilities/convention-on-the-rights-of-persons-with-disabilities-2.html. Accessed 6 May 2020.

Urry, John. 2007. Mobilities. Cambridge: Polity Press. 